\title{
Local Perception about Caesarian Section among Post Caesarian Section Women in
}

\author{
Pakistan \\ * Ikram Badshah, Assistant Professor \\ ** Zakiya Rubab Mohsin, MPhil Scholar \\ *** Jan Alam, Lecturer
}

\begin{abstract}
Birthing is a critical moment in the life of a mother. The biomedical practice of the Caesarian Section (C-section) does not exist in a vacuum but is under the influence of the sociocultural environment. However, deciding between methods of birth and the perception about the C-section shows a gap and dearth in the present literature. This paper aims at understanding what social and cultural factors construct the perceptions and experiences of the Caesarian Section among post-C-section-women belonging to different socio-economic statuses. Moreover, it explores how these factors influence Pakistani women's decision-making regarding childbirth methods. The paper uses a qualitative yet multi-sited locale approach, employing semi-structured interviews from 20 post-C-section women mainly from Islamabad and Rawalpindi region; 10 women belong to lower socio-economic status whereas, 10 to the upper one. Different themes from data were identified and obtained for analysis.

The perception and experience of the C-section fluctuate with social, economic, and cultural factors. The influence of biomedical and intra-household politics on the decision of $C$-section is much conspicuous and evident. Affluent families practice C-sections under dominant power dynamics without any reasoning. For those who can afford $C$-section, is perceived as a luxury and artificial motherhood in the eyes of "the others" whereas, normal birthing was true and natural motherhood. The social construction of the C-section suggests that social and culturalforces play a decisive role. $C$-section is only acceptable if there is an emergency otherwise natural birth is the most suitable method of childbirth. Along with advocating $C$-sections in critical medical conditions, an awareness campaign against $C$-sections is also imperative for it has severe consequences.
\end{abstract}

Keywords: Perceptions, Experience, Decision Making, Caesarian, Socioeconomic, VBAC (Vaginal Birth after Caesarian)

\section{Introduction}

The trend of Caesarian Section (C-section) has shown an increase worldwide whereas, according to the World Health Organization (WHO), the maximum range of C-section is $15 \%$ to save maternal and neonatal health. The reality on the ground paints a contrasting picture with no confirmation of associated reductions in neonatal morbidities or mortalities (Panda, et al., 2018). There is an increase of $4 \%$ in the worldwide rate of C-section while in Pakistan the percentage has reached $26 \%$ in urban settings and in Is lamabad's urban region the percentage reaches $33 \%$ with $23 \%$ in rural regions (Nazir, 2015). The caesarian section is one of the most common operating room procedures in the United States and subsequently in other developed and developing countries (Puia, 2018). A review of the literature suggests that only a few studies have thoroughly investigated the comprehensive Caesarian birth experience, starting from the process of decision making through the postpartum recovery along with the physical and emotional aspects of the birth. (Puia, 2018). The escalating rates of $\mathrm{C}$-sections call for a careful investigation to reveal the underlying factors contributing to this increase, particularly in recording the women's perception and experience about it.

Here the question arises that who decides for the C-section and what are the perceptions and experiences about $\mathrm{C}$-section in post-C-section mothers? What are the preferences in birthing methods and knowledge of the Caesarian section process among the post-C-section mothers? The local perception of mothers on $\mathrm{C}$-sections is a significant domain to explore from an anthropological

* Department of Anthropology, Quaid-i-Azam University Islamabad Ikram@qau.edu.pk

** Department of Anthropology, Quaid-i-Azam University Islamabad

$* * *$ Kohat University of Science and Technology, Kohat 
perspective to document the participant's point of view and their say in decision making about Csections. This paper illuminates the perceptions on $\mathrm{C}$-section that how post-C-section mothers view this surgical procedure as a method of delivering babies concerning their experiences.

\section{Methodology}

Recruitment and Participants

Anthropology lately has been more reflexive and "shifted from structure to practice or from pattern to process" (Hansen, 1997). Therefore, to intricately record the diversity of cases and population this multiple-site ethnographic study explores and analyzes the perception and experiences of C-sections among mothers conducted primarily in Rawalpindi and Islamabad with some cases from Faisalabad, Hafizabad, and Ahmedpur to record the perception about C-section covering the uneducated rural population (these cases were selected through snowball sampling). Oral consent from women was taken before conducting interviews, and confidentiality and anonymity were strictly ensured. A sample of 20 women was purposefully taken for qualitative interviews. The inclusion criteria for women was that all the females have had at least one Caesarian section. Respondents also included women who had both experiences of natural birth and the Caesarian section. It included women from a mix of social and economic statuses. The sample comprised 10 educated mothers and 10 uneducated or lesser-educated mothers. They are women from rural backgrounds in the majority of the cases. Other factors that were kept in the vision for the study were qualification, class, and family structure.

\section{Research Questions}

The knowledge about birthing methods and information about Caesarian Sections among the education mothers was hypothesized to be better than the uneducated mothers. The research was predictive of educated women considering that informed mothers have better knowledge about $\mathrm{C}$ sections and are active participants in decision making regarding modes of birthing and perceive CS as a safe option of birth. This research investigates the role of knowledge, education, family structure, class, and socioeconomic status in the perception and experience of the C-section in Pakistan. What are the perceptions and experiences of the post-C-section mothers regarding $\mathrm{C}$-section? How women with VBAC perceive the $\mathrm{C}$-section and what factors are responsible for the increase in the $\mathrm{C}$-section rate.

\section{Objectives}

The primary objective of this paper is to understand what social and cultural factors construct the perceptions and experiences of the Cesarean Section among post-Cesarean Section women belonging to different socio-economic statuses. Moreover, to explore how these factors influence Pakistani women's decision-making regarding childbirth methods.

\section{Data Collection}

This qualitative study used an interview guide and semi-structured questionnaire covering themes on knowledge, perception, and experience of the Caesarian Section. Data was collected through face-toface interviews, followed by telephonic conversations.

\section{Analytical approach}

All interviews lasted about one to two hours. Extensive field notes were taken to record the responses. The analysis was done qualitatively based on the response's skewedness on identified themes. Verbatim and quotation were carefully placed under proper and relevant themes.

\section{Key informants and assistance}

Two key informants were included in study one from the urban setting (Kiran) and one from the rural settings (Zeb). They further identified the relevant cases and also guided about the major perceptions of women regarding CS. Jibbi/downtown in Rawalpindi was also included in the study for including uneducated women. Dr. Khatija's clinic in Islamabad and Dr. Atta Memorial Hospital in Rawalpindi were visited and respondents were identified for the study.

\section{Findings}

\section{Perception about Caesarian Section concerning Qualification}

Regarding perceptions on the Caesarian section, expecting women still had no information about Csections which needs to be addressed (Ishaq, et al., 2017). Educated women in urban settings tend to have some better information regarding the Caesarian section than those who are less educated or uneducated. The educated women and women of higher strata opt for elective Caesarian sections according to various sources (Huesch, 2011). Celebrities and media is one factor that is promoting positive imaging of $\mathrm{C}$-sections despite the absence of any medical indication which calls for the 
operation (Weaver, Statham, \& Richards, 2007). Therefore, the elective Caesarian Section is in demand when the women of higher social strata (better socioeconomic class) make their judgment through following 'the others' experiences. Elective Caesarian sections are also opted for due to fear of labor pain or previous negative delivery experience (Huesch, 2011). Another interesting perception, which the study came across, was that Caesarian section babies are more likely to be smarter than those who are born through the natural method. Alvina, an educated working woman shared that she heard children born through $\mathrm{C}$-section are more intelligent therefore, she is looking forward to seeing her daughter as more intelligent (than her son) who was born through $\mathrm{C}$-section.

While reviewing the literature, several studies unveiled that education levels play a vital role in creating a positive image of $\mathrm{C}$-section. A study in Ghana on socioeconomic inequalities in the use of Caesarian section revealed that as the education levels increased among women, the rate of Csection also increased, with $33 \%$ of higher educated women and $6.1 \%$ among those who had no formal education (Dankwah, Kirychuk, Zeng, Feng, \& Farag, 2019). Similarly, a study in Pakistan and China showed that highly educated women are inclined towards having a C-section than those who are uneducated or have no formal education. Women with lesser knowledge are not active participants in decision-making about the birthing mode at the time of delivery (Dankwah, Kirychuk, Zeng, Feng, \& Farag, 2019). The research found that uneducated women associate natural birth with true motherhood and C-section with incapability of a mother or luxury. A study in Ghana concluded that women who are deprived of formal education and are unemployed show a poor perception of the Caesarian section and women see the Caesarian section as a reproductive failure whereas, vaginal delivery is a symbol of womanhood (Gandau, et al, 2019). Whereas, qualified/educated women tend to focus more on their health and are sensitive to baby's birth defects which may result in normal delivery therefore, educated women consider C-section as a safer option.

A study conducted in Germany on pregnant women to record their perception of elective Csections found that pregnant women perceived Caesarian sections based on their past experiences (Tschudin, et al., 2009). This research also experienced similar results that women in Pakistan tend to decide for their childbirth method based upon the ir previous childbirth experiences and stories from others. Knowledge sharing about $\mathrm{C}$-section and education are key players in decision-making about methods of delivery. 'Having listened to others' experiences, I prayed that I may deliver my baby naturally, (otherwise) who would take care of me and the chores if I get operated", said Naureen (Naureen, 2019). In the arena of knowledge and education, there is a dominant discourse that takes precedence over the local knowledge, which is also called authoritative knowledge. A comparative study was conducted by Sargent and Bascope in three diverse cultures about the ways of knowing about birth; in which it is explained that when more than one knowledge exists about a theme, certainly one knowledge takes precedence over the rest of them which is termed as authoritative or dominant know ledge (Jordan, 1997). This knowledge becomes reasonable and sharable with others to maintain its prominence, rationale for action, and reproduction of this knowledge for future implementation (Sargent \& Bascope, 1996). The knowledge acquired with the experiences of others had an impact on expecting mothers and usually, the scary stories take over the good ones (Naureen, 2019). The majority of the respondents told that the decision-making in modes of delivery is not much of a choice for the patient. Among uneducated people, doctors take the lead and decision power rests with the dominant medical knowledge/ doctors. 'I knew nothing, nor I used anything like the internet that I could know the intricacies of the procedure, I was just crying that I am going to have an operation. I was frightened of operation ", says Rizwana who attended school till grade 5.

Perceptions and experience of C-section were opposite in some women's cases. Romesa is an MPhil. in biogenetics tells her story, 'I didn't have any specific knowledge about the C-section as my pregnancy was all going normal till the end, I think ignorance is a bliss, I only knew that it's a surgical procedure but didn't know that there would be internal stitches also'.' Some thought it's a painless delivery but later realized that the aftercare of the Caesarian section involves more time and endurance. 'I thought I will receive my baby without any pain and continue to enjoy time with a newborn but I couldn't even hold and feed my girl for three days"' says Amna who had a Caesarian section by choice/elective C-section.

\section{Influe nce of Knowledge on Decision Making about Caesarian Section}

The scholarship on contemporary reproductive ideologies explains that women prefer to feel in control of their pregnancies, deliveries, and postpartum experiences (Fox \& Worts, 1999). Yet the 
decision about mode of delivery is not primarily made by the women themselves but the doctors and later the family to a fairly large ratio, women undergo an operation without their will (Shahid, 2013). Several factors influence women in decision-making about choices of delivering. Recent advancement in the obstetric is 'evidence-based medicine' which influences the patient's ability to make an independent decision through using the data of research papers, cohort studies, and case studies. Doctors and practitioners carefully select the data which they feel is objective, apolitical, and scientific (Wendland, 2007). The decision about C-section is tailored in such a fashion that it may feel that the autonomy of the expecting mother is ensured, whereas, studies have revealed that the counseling about birthing methods and particularly risks associated with natural delivery is amplified in general discussions by obstetric with the ir patients. 'My doctor told me about the risks involved in natural delivery, and told me that Caesarian section is the safest mode of delivery therefore, my husband decided that I should have an elective Caesarian section" said Hajra a post-C-section mother. This shows quite a vague picture of decision-making about methods of birth when the dominant knowledge uses superior structuralism to overpower the patient's views. The decisionmaking on modes of delivery depends on various factors yet who is the deciding authority is quite prominent in biomedical activity. A study in Nigeria has established that women often need to seek family members' and spousal consent to get medical advice let alone the decision about opting for Csection alone but decisions are made jointly (Ezeome, Ezugworie, \& Udealor, 2018). The decision about $\mathrm{C}$-section is perceived as a very sensitive matter of concern for the family so menfolk are influential in making final decisions. The gender bias is vividly seen throughout the course particularly in patriarchal societies (Kandiyoti, 1988), including decisions on women's medical condition at large.

Many respondents told that the stories and experiences of others influenced them to decide on an elective Caesarian section. Mostly the negative experiences and stories of long painful labor took precedence over positive ones (Puia, 2018) which made the women decide for a Caesarian section as an easy way out. Tallat a post-C-section mother did not have any information or knowledge about modes of birth, her sister had a C-section so she also thought this would be the only or best possible way of delivering the baby. She said, 'my elder sister also told me that $C$-section is easy, you just sleep and get your baby, there are no pains, I am happy with C-section it's better than labor pains and body de-shaping which may affect the marital life".

Furthermore, a study by Emile found that the fear and anxiety related to vaginal birth overpowers the consequences of a C-section and women opt for elective C-section to avoid the labor pains and messiness of natural birth (Reyes, 2018). Ecker's study found that women often go for an elective C-section as a defensive decision for the reason of having not being ready to bear the labor or risk perception of vaginal delivery, which are often highlighted in media, social interaction, emotions stories/ bad experiences of others (such as cerebral palsy or infant death) (Lake, 2012). It is warranted to say that the decisions about the childbirth method are influenced by several factors and are not decided by one. 'The trouble is, that ideal of a doctor and a patient making an objective and informed decision together is hard to come by" (Oster \& McClelland, 2019). Many respondents reported that they were not aware of the surgical procedure and its intricacies until they had gone through it. "It was a planned C-section so I was aware of most of the things but did not know about the medical complications and intricacies like "seven layers of my skin would be cut", told three respondents.

Perceptions did not turn out to be correct all the time, Kiran an educated mother who had both birthing experiences say, 'C-section stories were positive but it's worse than Vaginal Birth. I agree with elders who prefer vaginal birth because the recovery time is lesser and more smooth than $C$ section'.

As education plays an important role in decision-making about the delivery method, uneducated women's perspective is made through other women's experiences and stories of others as explained in the paper. Naheed, an uneducated post-C-section woman told that her sisters-in-law had an operation but she didn't ask them because she was reluctant and felt shame in talking about such topics.

\section{The Variance of Perception and Experience with Socioeconomic Start}

A critical review of literature on elective Caesarian section and decision making explores that there is little evidence to the correlation of increase in rates of $\mathrm{C}$-section and maternal request as a vital 
contributor to an escalation in C-section ratio. Which has been spread as 'Too posh to push' slogan by the media (McCourt, et al., 2007). "Middle-class women have been labeled "too posh to push" or have been accused of following celebrity trends for birth by Caesarian section"' (Weaver, Statham, \& Richards, 2007). According to an estimate, economic conditions also play a role in the decision about $\mathrm{C}$-section, the upper class seem to take no risks and pains associated with normal delivery as Dr. Rizwana also explains the increase in C-section nowadays (Shahid, 2013). The relationship between $\mathrm{C}$-section birth and socio-economic forecasters is well-established in literature yet some areas are under-researched on the issue at hand (Dankwah, Kirychuk, Zeng, Feng, \& Farag, 2019).

Perception about C-section in economically strong women doesn't include the budgetary constraint for payments for the operation therefore, the only concern left for these women is their health and their babies what they call 'had no other option' (Puia, 2018). Various studies have found that the percentage of $\mathrm{C}$-sections is higher among the richer or wealthier women than the poorer. In Bangladesh, the C-section rate is 2.5 times more among the rich population than the economically low population (Begum, et al., 2017). Normal deliveries are considered more painful and prone to risks as compared to Caesarian sections but are more prevalent among the poorer communities (Huesch, 2011). One reason for them is to be cost-effective and secondly, the recovery time is significantly less. Women with compromised economic conditions perceive the Caesarian section as much of a luxury for elite women or those who are in critical health conditions. 'I said to my husband operation is not for us, it is for high-class women or some for those with the serious illness of baby' says Falak Naz a $5^{\text {th }}$-grade pass ladies tailor told.

Another respondent explained that it was hard for her husband to arrange money for the Caesarian section, they had to borrow money and it took 15 days to arrange for the C-section fees. 'I went to Bakhhar (my hometown) for operation. They charge a lot of money for C-section in Bakhhar, 20 to 25 thousand rupees are taken in private hospitals", says underprivileged Naheed. Similarly, Sughra whose husband is a watchman had to wait for the committee money to manage finances for her operation. There is a strong perception of women regarding the Caesarian section that doctors do Caesarian section cause of money, doctors are making money and filling their pockets by doing unnecessary Caesarian sections (Rao, 2015).

Studies in developing countries have suggested that women prefer C-section in case of potential danger to mother or child health and no other option seems safe to the doctors, furthermore, women prefer C-section as a good thing to avoid labor pains and complications at the time of delivery (I Sunday-Adeoye, 2011). ' When I had labor pains and they started to increase, I could not bear the pains and told the nurse to call the doctor and get me operated on" Zahida from a better socioeconomic class who had C-section two weeks ago.

Another aspect that I came across during the research was the medical insurance in either government employees or private employees. The ratio of having a C-section is more among people whose medical is funded by their employers. "My husband is in Nescom, we had nofinancial issue in paying for the Caesarian section, I had an elective C-section for the safety of my baby", says wife of a government official. When the money is to be paid by the organization, people don't consider the Caesarian section as much of an issue. A study on the association between health insurance and elective Caesarian section revealed a positive correlation between Caesarian sections and insured women (Huesch, 2011). Wang studied the Caesarian Delivery on Maternal Request (CDMR) in China and found that the educated and informed mothers who had their health insurance cover opted primarily for C-sections (Wang, 2016). The research study conducted in Pakistan also found that women residing in the better locality as urban settings and have better economic conditions opt for the Caesarian section more than those who are living in rural areas and are economically disadvantaged (Mumtaz, Bahk, \& Khang, 2017). 'The greatest increase was seen in women with a higher educational level and those in the richest wealth quintile' (Mumtaz, Bahk, \& Khang, 2017). A study in Ghana also revealed that economically poorer women perceived $\mathrm{C}$-section as a long term disease as the recovery time is longer after $\mathrm{C}$-section and it keeps women from doing their domestic chores and economic affairs therefore they avoid C-section and widespread of such perceptions runs in the community (Gandau, et al., 2019).

\section{Perception about Caesarian Section concerning Family Structure}

Women who lived in the joint family system faced lesser issues regarding childrearing and healthcare practices, particularly where the husbands are present e.g. women living alone tend to have low birth 
weight babies or with some other defects (Ramsey, Abell, \& Baker, 1986). Living alone is very tough, having an operation and kids to look after alone was very hectic. My husband used to go to work and return late, leaving me alone on my own. At the time of the second child, I asked for a maid, who helped me with household chores. I used to just keep crying all day repenting of what is happening with me, a respondent from the nuclear family system told me. Rizwana and uneducated post-Csection mother said that it's very hard for women who live in nuclear families, there are many people to take care of if one lives in a joint family.

The findings depicted that the Joint family system, where it provides the women with human resources for looking after the newborn, also takes the toll on women's autonomy in decision making. In traditional families, the decision is taken by elderly women particularly mothers-in-law or husbands but rarely the woman/expecting mother herself (Kandiyoti, 1988). "'After the doctor recommended $C$-section for I had a precious pregnancy, after three years of marriage, my mother-inlaw decided that I will have C-section at any cost despite the fact I had no complications and could try normal delivery', one responded regretted the decision. Here we see decision powers lying with elderly women and the influence of biomedical discourse on opting for C-section. The influence of family tradition on methods of delivery is significant and causes psychological effects on expecting mothers and vice versa (S.Mutryn, 1993). 'Only my sisters have C-section, not anyone else in the family. Relatives say we sisters don't like to bear the pains of childbirth and go for operations by choice but it's very painful', Falak a post-C-section mother who lives in a joint family tells. Moreover, it was observed during my research that the concept of privacy in the joint family system is not much appreciated, male members other than husbands are kept at a distance from women's health issues to an extent but other women in a family share their issues.

Selflessness and enduring pain are taken as an attribute of true femininity and a "proper" way of attaining the rites of passage of motherhood (Malacrida \& Boulton, 2012). To bear the pain is one way of proving one's femininity and a superior form of motherhood. Women usually feel that natural delivery is "ideal motherhood" and if someone opts for a C-section, she is tagged with 'false motherhood' or an 'artificial mother' by other women arguing the superiority of experience of natural birth (Freeman, 2016; Malacrida \& Boulton, 2012). Mothering with pain is associated with true motherhood and femininity, a mother has to undergo labor to deserve the due status according to traditional mothers. " A "real woman" has to bear the pains of labor no matter how long it lasts and subsequently delivers a healthy baby vaginally" (Ezeome, Ezugworie, \& Udealor, 2018). Kiran, a civil servant told that her mother-in-law used to tell her time and again, 'this is my brave girl, she will deliver the baby naturally" it was constantly told that natural de livery is the right way to motherhood and C-section is just an artificial method of doctors. The study illustrates that the decision about mode of delivery is not primarily made by the women themselves but the doctors and later the family (to a fairly large ratio), women undergo an operation without their will (Shahid, 2013; Oster \& McClelland, 2019). Perceptions about methods of birth are in constant flux until the time of delivery and women tend to have a confused state of mind by listening to stories of other women. They have an influence on the outcome of pregnancies living in joint families, stories of long painful labor (Puia, 2018) or Caesarian section as not an option for some. During data triangulation when talked to a doctor she told that operations are not a trend in some families, like some Pashtun women may have home births just to avoid doctors and C-sections. Another doctor told, 'these women with rigid tradition may prefer dying than to go for a C-section"

A comparative study on housework and gender roles in extended and nuclear families finds women living in the nuclear family system face hardships in childrearing due to a load of domestic chores burden on women themselves but have greater autonomy as compared to women in joint family systems (Sun, 2008). Furthermore, it explained the presence of grandparents in the house puts a lesser workload on women, Shehzil a working woman accepts that she was able to continue work after children due to the kid's grandparents who look after them when she goes to work (Shehzil, 2019). In addition to extended cooperation of family members, the role of husbands was also found significant in pregnancy and the postpartum period. 'My husband is supportive but does what he wants to do, men are superior because God has made them superior. He doesn't help me with chores otherwise family members and relatives make fun of him. Decisions are taken by my husband and I obey him, says a post-C-section mother living in a joint family. 
On the other hand, Naheed believes her husband is a good man, he was worried when he came to know that her wife would have an operation. 'He didn't say anything to me but I could tell by his face that he was upset because I was going to have an operation", said Naheed.

The research also investigated the post-C-section complications and aftercare practices and experiences among $\mathrm{C}$-section women. A post-C-section working mother living in a joint family explained, "aftercare of C-section wound is not easy, I got an infection soon after birth, but luckily my brother-in-law who is a surgeon treated me on time and gave me some antibiotics that I got recovered in 2-3 weeks but I couldn't do any household chores for one year'. Another respondent whose husband is an overseas Pakistani and she lives with in-laws told that her mother-in-law used to clean her C-section inc ision wound, 'it was great to help that my mother-in-law took care of me when I could not even go to the restroom alone'". With my first child and C-section, it was a nightmare to take care of an infant and myself, only my husband was the helping hand who had to go to the office also. With my second child, my mother-in-law came to my place and helped me with taking care of my kids. It's a positive thing to live in a joint family. Another respondent living in a joint family told, "although my in-laws are very supportive and understanding when I had normal delivery they were happier than the time I had C-section'.

Postpartum depression is commonly faced among C-section mothers mainly due to limitations of mobility due to operation and prolonged recovery time. Respondents who had VBAC experiences and C-sections stated that the duration and intensity of depression after natural delivery were less. ' $I$ was depressed apparently for no reason, I would just sit and cry and fight with my husband over pity issues. I was in pain and could not manage many things with two kids", recalled a respondent. Postpartum anxiety takes different shapes and stays for different periods. The findings concluded that the trauma of surgery disturbed the women primarily, secondly, the role of husbands played a significant role in bringing their wives back to normal life.

\section{Discussion}

In reproductive health, the first continuum of care starts from pregnancy to birth and post-birth Childbirth is a phenomenal occurrence in the lives of mothers to which they have different perceptions and experiences (Puia, 2018). The research found that there is a difference in perception about C-section and experience. Women have relied on the information received from other women in a family which had influenced the decision-making process in choosing the method of birth. Nafeesa a 36-year-old government officer who had both experiences of a C-section and VBAC shares, 'I had learned through several women that vaginal birth is very painful but didn't know it was that intense, the knowledge got from the mother-in-law and my mother was mostly myth-based... there is a difference between stories and reality'.

Further, it was also seen that doctors and paramedical staff play a significant role in shaping perception about $\mathrm{C}$-section which is projected as a safer method of delivery that involves no risk to mother and child. 'I had knowledge of normal delivery but did not try for it because my doctor had already made my mind for Caesarian section", a post-C-section mother responded. The authoritative knowledge serves as dominant knowledge among the mothers and families that often supersede the traditional one which is also termed as structural superiority (Jordan, 1997). This structural superiority is witnessed in biomedical discourse generally, based upon the authority associated with position/authority or knowledge. Similarly one stated, "my husband trusted the doctor more than any other person, always made me decide for what the doctor wanted without my consent, 100\% doctor's advice was followed throughout pregnancy and in the end, I had a C-section".

Using Michael Foucault's notion of power, know ledge, and episteme, an absolute relationship is witnessed between the scientific episteme and the community. Knowledge is shaped as social construction by prior knowledge and a posteriori knowledge (Casullo, 2010). In either case, the scientific episteme supersedes the local perception and is constructed unconsciously. The medical discourse display power over the common population, the expecting mothers and families. The hegemonic practice of $\mathrm{C}$-section in wake of economic interests of the doctors and hospital management in Pakistan is an open secret to many (Ihsan, 2018).

Through careful analysis of the responses concerning decisions about methods of delivery, we found that this perception has often led women to undergo serious health issues where they opt for a natural delivery or VBAC when C-section must have been the priority. The two reasons found through this research are whether they don't afford a hefty amount of money for C-section and 
hospital stay or it's a traditional limitation to have children with the operation. The sorry state of our medical system entails that cases, where C-section is inevitable and necessary (the lower strata women with a genuine medical condition), are tried for natural childbirth whereas, the elite class gets the facility accessible even if unnecessary.

Post-Caesarian section mothers perceived their knowledge as unsatisfactory about operation procedure and intricacies particularly in the recovery period and that seven layers of skin are cut in Csection. The results have found that educated mothers are skeptical of vaginal birth (cause of associated complications), along with an interesting perception about C-section babies that they are likely to be smarter than the babies who are delivered vaginally. Khadem and Khadivzadeh study found this perception as grey area in a study conducted in Iran examining the association between intelligence quotient and Caesarian section children. Show ing slightly higher IQ of C-section children but were also born to educated parents (Khadem \& Khadivzadeh, 2010). Moreover, the study found the rate of C-section is higher in educated women, therefore, suggesting that the higher IQ is due to maternal education, not Caesarian section birth (Khadem \& Khadivzadeh, 2010).

During the research, we came across interesting perceptions of body imaging in post-Csection mothers, some were of the view that C-section keeps the women's body in shape whereas, normal delivery can cause de-shaping of the body (Huesch, 2011). Educated and upper socioeconomic class women sometimes go for elective $\mathrm{C}$-sections in hope of maintaining their figures. This perception was denied in a discussion with women who had both experiences of $\mathrm{C}$-section and vaginal birth. It is also perceived that birth spacing of more than three years can add to the prospects of having VBAC (Vaginal birth after Caesarian). 'I am using contraceptives for birth spacing because I have heard that it is possible to have normal delivery if there is a gap of three years"', a respondent shared.

Stories of post-C-section mothers revealed that perspective and experiences of C-section vary from case to case based on different factors that include qualification, husband's attitude, family structure, socioeconomic conditions, aftercare, and availability of resources. Perception about Csection in a few cases was very positive but the experience of women was opposite to what they heard and recovery of Caesarian section wound and other health concerns take more time than natural delivery which was found one factor women disliked C-section. Another health concern associated with C-section was found to be postpartum depression, most of the women with C-section perceived postpartum depression as an inevitable side effect of Caesarian section. The operation makes it hard for new mothers to manage their newborns and domestic chores while doing post-operative care.

\section{Conclusion}

The sociocultural context constructs the perception and experience of CS among women. The privatization and biomedical practices of CS are associated. The women's perception and practice about CS fluctuate with social and economic capitals. Local perception of the Caesarian section was observed positive for it had lesser pain and safest birth method but the experiences of women showed it as more painful and time-consuming in recovering. Women with better education, socioeconomic status, and living in the nuclear family showed a higher tendency for opting for elective Caesarian section and consider $\mathrm{C}$-section as the safest option in birthing methods. Knowledge about $\mathrm{C}$-sections was not satisfactory among the expecting mothers and the decision about CS was not made by themselves but was influenced by some factors which included doctor's suggestions, family pressure, health condition, and economic status. Those who had gone for C-section by choice or not, or had both the experiences of birth shared that normal birth must be better than the $\mathrm{C}$-section. Another perspective of women was that knowledge about operation makes you scared of the process, ignorance is bliss according to many post-C-section mothers, the first time was easier for them to undergo the procedure but the second times are the hardest because they know what will happen to them. More informed women knowing $\mathrm{C}$-section made better choices or influenced the decisionmaking process if they were not the sole decision-makers. It is concluded that the interplay of power and know ledge, and structural superiority, and dominant knowledge are prevalent in the given society with prominent influence and practice in the biomedical world.

\section{Recommendations}

A high trend for C-sections warns that the World Health Organization's recommended percentage for $\mathrm{C}$-sections is causing healthcare issues therefore, it is a serious matter to revisit by both the public and doctors. There must be strict guide lines in opting for $\mathrm{C}$-section such as trial for a vaginal birth at all levels until C-section becomes inevitable. Doctors and paramedical staff should guide the patients 
properly and discuss all possible complications as a result of any medical procedure during childbirth. Better-off are ready to accept it without question and objection; for poor it is a luxury and there is no requirement for this as such. There is a need to take a middle position because it is neither a luxury nor a thing without consequences. C-section birthing must not be used except for saving the life of the mother and infant. The application of a C-section is only justifiable in an emergency.

There are some limitations of the study as a small sample of 20 respondents cannot represent the whole society. However, for qualitative ethnographic research, the purpose of the study is not to follow and maintain representation and generalization.

References

Begum, T., Rahman, A., Nababan, H., Hoque, D. M., Khan, A. F., Ali, T., \& Anwar, I. (2017). Indications \& determinants of cesarean section delivery: Evidence from a population-based study in Matlab, Bangladesh. PLoS ONE, 11(12). doi:10.1371/journal.pone.0188074

Casullo, A. (2010). A Priori Knowledge. In J. DANCY, E. SOSA, \& M. STEUP (Eds.), A Companion to Epistemology (second ed., p. 43). Sussex, UK: Wiely-Blackwell.

Dankwah, E., Kirychuk, S., Zeng, W., Feng, C., \& Farag, M. (2019). Socioeconomic inequalities in the use of cesarean section delivery in Ghana: a cross-sectional study using nationally representative data. International Journal for Equity in Health, 18(162). doi:10.1186/s12939019-1063-6

Ezeome, I., Ezugworie, J., \& Udealor, P. (2018). Beliefs, perceptions, \& views of pregnant women about Caesarian section \& reproductive decision-making in a specialist health facility in Enugu, Southeast Nigeria. Nigerian Journal of Clinical Practice, 21 (4), 423-428.

Fox, B., \& Worts, D. (1999, June). Revisiting the Critique of Medicalized Childbirth: A Contribution to the Sociology of Birth. Gender \& Society, 13(3), 326-346.

Freeman, H. (2016, April 02). There is nothing wrong with a C-section - so let's quit judging other mothers. Retrieved October 09, 2019, from The Guardian: https://www.theguardian.com/ lifestyle/2016/Apr/02/nothing-wrong-C-section-quit-judging-mothers-Hadley-freeman

Gandau, B. B., Nuertey, B. D., Seneadza, N. A., Akaateba, D., Azusong, E., Y irifere, J. Y., . . . Tette, E. M. (2019). Maternal perceptions about cesarean section deliveries \& their role in reducing perinatal \& neonatal mortality in the Upper West Region of Ghana; a cross-sectional study. BMC Pregnancy Childbirth, 19(350). doi:10.1186/s12884-019-2536-8

Hansen, H. P. (1997). Patient's bodies \& discourses of power. In C. Shore, \& S. Wright (Eds.), Anthropology of policy: critical perspectives on governance \& power (pp. 68-80). London: Routledge.

Huesch, M. D. (2011). Association Between Type of Health Insurance \& Elective Caesarian Deliveries: New Jersey, 2004-2007. American Journal of Public Health, 101(11), e1-e7.

Huesch, M. D. (2011). Association Between Type of Health Insurance \& Elective Caesarian Deliveries: New Jersey, 2004-2007. American Journal of Public Health, 101(11), e1-e7.

Ihsan, A. (2018, May 20). C-section; a need or business. Lahore, Pakistan: The Nation.

Jordan, B. (1997). Authoritative knowledge \& its construction. In R. E. Davis-Floyd, \& C. F. Sargent (Eds.), Childbirth \& authoritative knowledge: cross-cultural perspectives (p. 56). Berkeley: University of California Press.

Kandiyoti, D. (1988, September). Bargaining with Patriarchy. Gender \& Society, 2(3), 274-290. doi:10.1177/089124388002003004

Khadem, N., \& Khadivzadeh, T. (2010). The intelligence quotient of school-aged children delivered by Caesarian section \& vaginal de livery. Iranian Journal of Nursing \& Midwifery Research, 15(3), 135-140.

Lake, N. (2012, November-December). Labor, Interrupted; Caesarians, "cascading interventions," \& finding a sense of balance. Harvard Magazine, pp. 21-26. Retrieved from https://harvardmagazine.com/2012/11/labor-interrupted

Loke, A. Y., Davies, L., \& Mak, Y.-w. (2019). Is it the decision of women to choose a Caesarian section as the mode of birth? A review of literature on the views of stakeholders. BMC Pregnancy \& Childbirth, 19(286). doi:10.1186/s12884-019-2440-2

Malacrida, C., \& Boulton, T. (2012). WOMEN'S PERCEPTIONS OF CHILDBIRTH "CHOICES": Competing Discourses of Motherhood, Sexuality, \& Selflessness. Gender \& Society, 26(5), 748-772. 
Mumtaz, S., Bahk, J., \& Khang, Y.-H. (2017). Rising trends \& inequalities in Caesarian section rates in Pakistan: Evidence from Pakistan Demographic \& Health Surveys, 1990-2013. PLoS ONE. doi:doi.org/10.1371/journal.pone.0186563

Naureen. (2019, November 23). Perception about C-section. (Z. R. Mohsin, Interviewer)

Oster, E., \& McClelland, W. S. (2019, October 17). Why the C-section Rate Is So High; A doctor \& an economist note that doctors are generally paid quite a bit more for a $C$-section than for a vaginal birth. Retrieved from the Atlantic: https://www.theatlantic.com/ideas/archive/ 2019/10/ C-section-rate-high/600172/

Puia, D. (2018). First-Time Mothers' Experiences of a Planned Cesarean Birth. The Journal of Perinatal Education, 27(1), 50-60.

Puia, D. (2018). First-Time Mothers' Experiences of a Planned Cesarean Birth. The Journal of Perinatal Education, 21(7), 50-60.

Ramsey, C. N., Abell, T. D., \& Baker, L. C. (1986). The Relationship Between Family Functioning, Life Events, Family Structure, \& the Outcome of Pregnancy. THE JOURNAL OF FAMILY PRACTICE, 22(6), 521-527.

Rao, A. (2015, January 15). Caesarian births in India are skyrocketing — \& there is reason to be very worried. India: Quartz India.

Reyes, E. (2018). MATERNAL MOTIVES BEHIND ELECTIVE CAESARIAN SECTIONS. The University of Delaware. Retrieved from file ://D :/C-section/Reyes,\%20Emaline\%20elective\% 20C-section\%20thesis.pdf

S.Mutryn, C. (1993). Psychosocial impact of the Caesarian section on the family: A literature review. Social Science \& Medicine, 37(10), 1271-1281. doi:10.1016/0277-9536(93)90338-5

Shahid, J. (2013, November 25). Private hospital thriving on Caesarian sections. Retrieved from Dawn.com: https://www.dawn.com/news/1058406

Shehzil. (2019, November 22). Issues of working women \& C-section. (Z. Rubab, Interviewer)

Sun, S. H.-L. (2008). Housework \& Gender in Nuclear Versus Extended Family Households: Experiences of Taiwanese Immigrants in Canada. Journal of Comparative Family Studies, 39(1), 1-17.

Wang, E. (2016). Choice, Control \& Childbirth: Caesarian Deliveries on Maternal Request in Shanghai, China. Anthropology Senior Thesis. Pennsylvania, USA: ScholarlyCommons.

Wendland, C. L. (2007, June). The Vanishing Mother: Caesarian Section \& "Evidence-Based ObstetriC-section". Medical Anthropology Quarterly, 21(2), 218-233. 